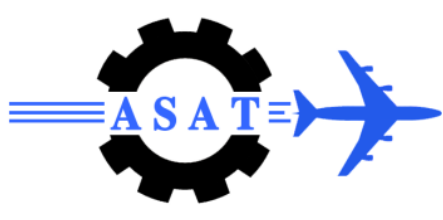

\title{
Effect of Cannabinoids (WIN55,212-2) in Acceleration of Wound Healing in Bone Cell Monolayer
}

\author{
M. Genedy ${ }^{*}$, M. Youseffi ${ }^{\dagger}$, F. Sefat ${ }^{*}$, A. Abdeldayem ${ }^{*}$ and M.C.T. Denyer ${ }^{\dagger}$
}

\begin{abstract}
Despite the ongoing political debate regarding the legality of medical marijuana, clinical investigations of the therapeutic use of cannabinoids are now more prevalent than at any time in history. Cannabinoids have been shown to have analgesic, anti-spasmodic, anticonvulsant, anti-tremor, anti-psychotic, anti-inflammatory, anti-oxidant, anti-emetic and appetite-stimulant properties. There are mainly two well known cannabinoid receptors, CB1 and CB2, located in the central and peripheral nervous systems as well as immune system, respectively. More recently, endocannabinoids (ligands) and their receptors have also been found in the skeleton which appears as the main body system physiologically regulated by CB2. The purpose of this investigation was to study the rate of wound healing using a scratch assay wound model created on MG63 bone cell-line monolayer and also to investigate proliferation and migration with and without the presence of cannabinoid WIN55, 212-2. Wounds were made (with average scratch width of 300|am $\pm 10-30 \mid \mathrm{am} \mathrm{SD,} \mathrm{1.7-5|am} \mathrm{SEM)} \mathrm{on}$ confluent monolayers. After wounding, culture flasks were treated with the synthetic cannabinoid (WIN 55,212-2) with concentrations of $0.6 \mid \mathrm{ag} / \mathrm{ml}$ and $0.9 \mid \mathrm{ag} / \mathrm{ml}$ and a non-treated control and ethanol (as solvent). It was found that addition of synthetic cannabinoid closed the wound completely after 30 hours whereas the control showed no sign of complete wound closure after 30 hours with $25 \%$ of wound still remained open. The rate of wound closure was found to be higher with cannabinoid additions. These findings suggest the potential use of synthetic cannabinoid (WIN 55,212-2) for achieving complete wound closure at a faster rate.
\end{abstract}

Keywords: MG63 Bone Cell Monolayer, Synthetic Cannabinoid (WIN 55,212-2), Scratch Assay Wound Model.

\section{Introduction}

Over the last 30 years or so researchers have been trying to establish and validate the role and use of cannabinoid in treating different conditions in human body and one of the emerging approaches is its use in bone proliferation and differentiation leading to increased bone formation and bone mass [1,2]. Functional endocannabinoid systems are present in several mammalian organs and tissues. Recently, endocannabinoids (endogenous cannabinoid receptor ligands) and their receptors have been found in the skeleton [1]. Osteoblasts, the bone forming cells, and osteoclasts, the bone resorbing cells, produce the endocannabinoids anandamide and 2-arachidonoylglycerol and express $\mathrm{CB}_{2}$ cannabinoid receptors $[1,2]$.

\footnotetext{
* School of Engineering, Design and Technology-Medical Engineering Department, Institute of Pharmaceutical Innovation, University of Bradford, Bradford BD7 1DP, UK.

$\dagger$ School of Engineering, Design and Technology-Medical Engineering Department.

$\$$ Institute of Pharmaceutical Innovation, University of Bradford, Bradford BD7 1DP, UK.
} 
Although $\mathrm{CB}_{2}$ has been implicated in pathological processes in the central nervous system and peripheral tissues, the skeleton appears as the main system being physiologically regulated by $\mathrm{CB}_{2}$ [1]. In humans and other vertebrates alike, bone structure undergoes substantial temporal changes throughout life. These changes comprise: (i) a rapid skeletal growth phase (ii) a steady-state phase whereby bone mass remains constant; and (iii) agerelated bone loss [2]. These changes are the natural homeostasis of bone throughout life and any disturbance would lead to imbalance leading to diseases such as osteoporosis and bone related conditions $[3,4]$.

$\Delta^{9}$-tetrahydrocannabinol $\left(\Delta^{9}\right.$-THC) has been found to be the main psychoactive component of cannabis and considered to be lipophilic having the ability to dissolve in fats, oils, lipids, and non-polar solvents such as hexane or toluene and relatively nonselective for both receptor subtypes $\mathrm{CB}_{1}$ and $\mathrm{CB}_{2}[2,5,6,7]$. However, its presence may or may not be as effective in bone repair due to mainly psychoactive properties. The present study investigated the effect of synthetic cannabinoid WIN55, 212-2 on wound closure response and healing rate of scratched bone cell monolayers via measuring the change in the model wound width during migration of cells into the wound bed as compared to control and ethanol (as solvent). These studies may form the basis for the identification of a potentially novel non-steroid based drug for the purpose of anti-arthritic and faster wound healing of bone and other tissues such as cartilage.

\section{Materials and Methods}

\section{Cell Seeding and Culture}

Glucose Dulbecco's Modified Eagle Medium (DMEM, SIGMA) containing various supplements such as L-glutamine $(4 \mathrm{mM})$, Penicillin-Streptomycin $(5 \mathrm{ml})$, fungizone $(1 \mathrm{ml})$, HEPES buffered culture medium and 'fetal calf serum' $(50 \mathrm{ml})$, was used. Cells were cultured in control medium with a seeding density of $50 \times 10^{4}$ cells $/ \mathrm{ml}$ in $\mathrm{T} 25 \mathrm{~cm}^{2}$ culture flasks and left for two days to reach confluency, after which a wound scar was made using $1 \mathrm{ml}$ pipette.

\section{Scratch Assay Wound Model}

After reaching confluency, a wound (scratch) was made using a $1 \mathrm{ml}$ disposable sterile long nosed plastic pipette. The tip was bent and drawn across the cells on the cultured surface creating the wound. The scratch markings facilitated orientation while imaging and another wound was later applied at 90 degree angle to the initial scratch and images were also taken at the cross points. Thus the same points were imaged which gave accurate and reliable data for analysis. The average scratch width produced for all different culture flasks were $\sim 350 \mu \mathrm{m} \pm 10-30 \mu \mathrm{m} \mathrm{SD}, 1.7-5 \mu \mathrm{m}$ SEM.

\section{Preparation Protocol for Synthetic Cannabinoid}

Prior to wounding, the synthetic cannabinoid WIN55, 212-2 (WIN-2) solution was prepared by dissolving the as received WIN-2 powder in $99.5 \%$ pure (absolute) ethanol (used as the solvent). Therefore, $6 \mathrm{mg}$ of WIN 55,212-2 was added to $1 \mathrm{ml}$ of ethanol to gain concentration of $6 \mathrm{gm} / \mathrm{mL}$ and was stored at $4^{\circ} \mathrm{C}$ as stock solution as advised by the supplier. Then, $0.1 \mathrm{ml}$ of the stock solution was added to $0.9 \mathrm{~mL}$ ethanol to reach a concentration of $0.6 \mathrm{mg} / \mathrm{mL}$ of WIN-2, out of which $5 \mu \mathrm{l}$ was added to $5 \mathrm{~mL}$ culture media to make $0.6 \mu \mathrm{g} / \mathrm{ml} \mathrm{WIN-2}$ as the final concentration for test 1 and monitored for a period of 30 hours after wounding. The same procedure was repeated by adding $9 \mathrm{mg}$ of WIN 55,212-2 to gain a concentration 
$0.9 \mathrm{mg} / \mathrm{mL}$ of WIN-2, out of which $5 \mu \mathrm{l}$ was added to the culture media to make a final concentration of $0.9 \mu \mathrm{g} / \mathrm{ml} \mathrm{WIN-2}$ as test 2 .

$5 \mathrm{~mL}$ of complete culture media was then added to each culture flask after scrathing. One culture flask was used as control, another one was treated with $5 \mu$ l of pure ethanol as negative control, and the $3^{\text {rd }}$ and $4^{\text {th }}$ flasks were diluted by adding $0.6 \mu \mathrm{g} / \mathrm{ml}$ and $0.9 \mu \mathrm{g} / \mathrm{ml}$ WIN 55,212-2 (as final concentrations). The four culture flasks were then inverted and put in the incubator at a temperature of $37^{\circ} \mathrm{C}$ under $95 \%$ air and $5 \% \mathrm{CO}_{2}$ for a period of 30 hours during which monitoring and imaging was preformed every 5 hours with the aid of image $\mathrm{J}$ software. These experiments were repeated three times to make sure about repeatability and accuracy of the results with minimum errors. Image $\mathbf{J}$ software was also used in order to measure the distance between the wound edges. Ten vertical lines at semi-random horizontal distances were drawn and the distances between the intersections of the lines with the wound edges were measured as shown in Figure 1.

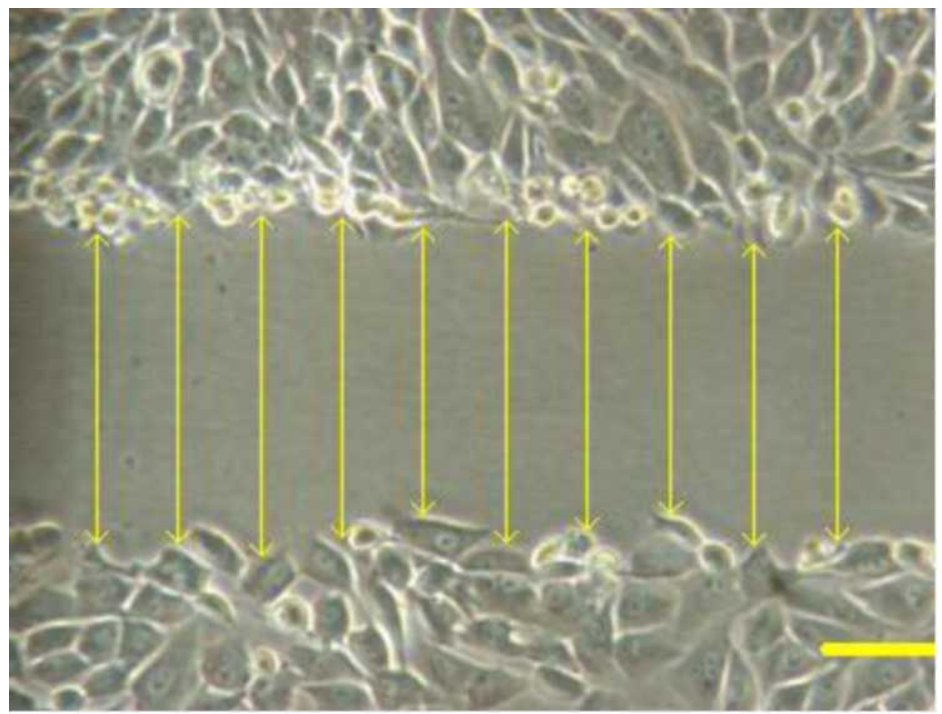

\section{Figure 1 Measurement of wound closure width on cultured MG63 bone cell monolayer with or without presence of cannabinoid, using 'Image J' software. (Error bar $=100 \mu \mathrm{m}$ ).}

\section{Proliferation Test}

A proliferation test was carried out for the non-treated cells as control (group C1) and treated cells (group C2) with WIN 55,212-2. The control and treated cells were left to attach and proliferate for 24 hours and then trypsinized using $0.25 \%$ Trypsin-EDTA after which a haemocytometer was used to count the number of cells for proliferation studies.

\section{Results and Discussion}

After preforming three repeats, it became clear that synthetic cannabinoid WIN-2 with different concentrations of $0.6 \mu \mathrm{g} / \mathrm{ml}$ and $0.9 \mu \mathrm{g} / \mathrm{ml}$ improved the wound healing of MG63 bone cell monolayers. The laboratory experiments indeed showed a positive effect with the administration of different concentrations of cannabinoid on wound closure response of MG63 bone cell monolayer. Figure 2 shows all four wounded bone cell monolayers together 
during 30 hours of healing with different concentration of cannabinoids at $0.6 \mu \mathrm{g} / \mathrm{ml}$ and $0.9 \mu \mathrm{g} / \mathrm{ml}$, ethanol and control.

Images for the wound closure process of the control culture flask show that there is no change in wound width even after 10 hours. Cell morphology changes can be observed only in the cells at the wound edges after 15 hours. These cells have elongated but without migration to the wound site. After 20 hours there were still gaps between the edges in the wound site. The cells in the control flask did not seem to form bridges with cells from the opposite wound edge to stabilize the wound site until $\sim 25$ hours. Cells from opposite sides meet each other and started making bridges after $\sim 25$ hours, but without complete closure. It was clear that wound still remained open even after 25 hours and that after 20 hours $\sim 40 \%$ of the wound still remained open for the control. It follows, therefore, that wound healing occurred very slowly in control culture flasks and $\sim 25 \%$ of wound remained open even after 30 hours as can be seen from graphs in Figures 3A and B. For WIN 55,212-2 additions, the percentage of wound remained open after 25 hours was only $~ 13 \%$ as compared to control group of $\sim 32 \%$. From Figure 3 it can be seen that percentage of wound remained open for WIN 55,212-2 additions, after 20 hours, was $\sim 15 \%$. However, control and ethanol gave values of $\sim 40 \%$ and $\sim 20 \%$, respectively, after $20 \mathrm{hrs}$, whereas a total of $\sim 95 \%$ wound closure occurred for WIN 55,212-2 additions after this period. After 25 hours, only $70 \%$ and $88 \%$ wound closure took place for both control and ethanol, respectively.

Images showing the wound closure process for the $0.9 \mu \mathrm{g} / \mathrm{ml}$ cannabinoid culture flask show that after 10 hours the morphology of the cells at the wound edges have changed and that the cells had elongated, spread, replicated and migrated into the wound site and perpendicularly to the wound axis. The vertically elongated cells look different (more elongated) to the cells a distance away from the wound edges which were more rounded. The cells seem to be less dense and more spread out at the wound edges. After 15 hours the cells had migrated further into the wound site and elongated in order to meet cells from the opposite side of the wound. These cells then formed bridges to connect the wound edges and close the wound gap. As soon as the had bridges formed in the wound site the wound was closed quite rapidly as can be seen from Figure 4 describing the rate of wound closure every 5 hours. The increased rate of wound closure for $0.9 \mu \mathrm{g} / \mathrm{ml}$ concentration can be seen in Figure 4 as it reached a maximum of $22 \mu \mathrm{m} / \mathrm{h}$ in the $1^{\text {st }} 10$ hours compared with control being the least with a value of $6.5 \mu \mathrm{m} / \mathrm{h}$. Furthermore, Figure 5 describes wound width closure over a period of 30 hours with a tendency of having a linear rate especially up to 15 hours and reduced rate up to 30 hours with an obvious variation in the slope between different test groups and control. Table 1 gives a summary of the slope (gradient) for each curve in Figure 5. From Table 1, it can be seen that the rate of wound closure is higher for the WIN 55,212-2 additions as compared to control indicating the positive effect that cannabinoid has in cell survival, migration and proliferation leading to faster healing. 


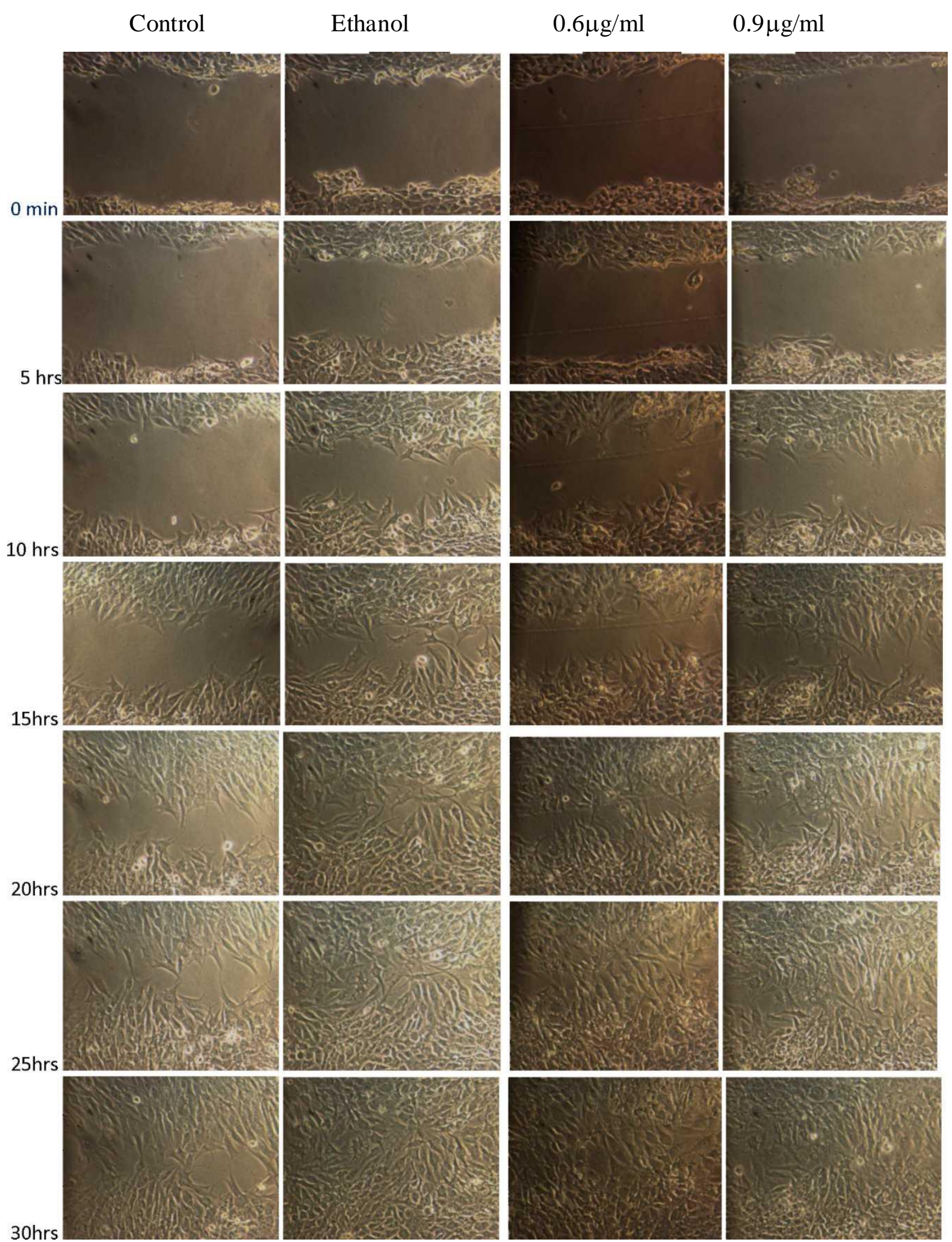

Figure 2 Images of the wound healing process for the bone cell monolayers with $0.6 \mu \mathrm{g} / \mathrm{ml}$ and $0.9 \mu \mathrm{g} / \mathrm{ml}$ of cannabinoids, ethanol and control (scale bar $=100 u m$ ). 


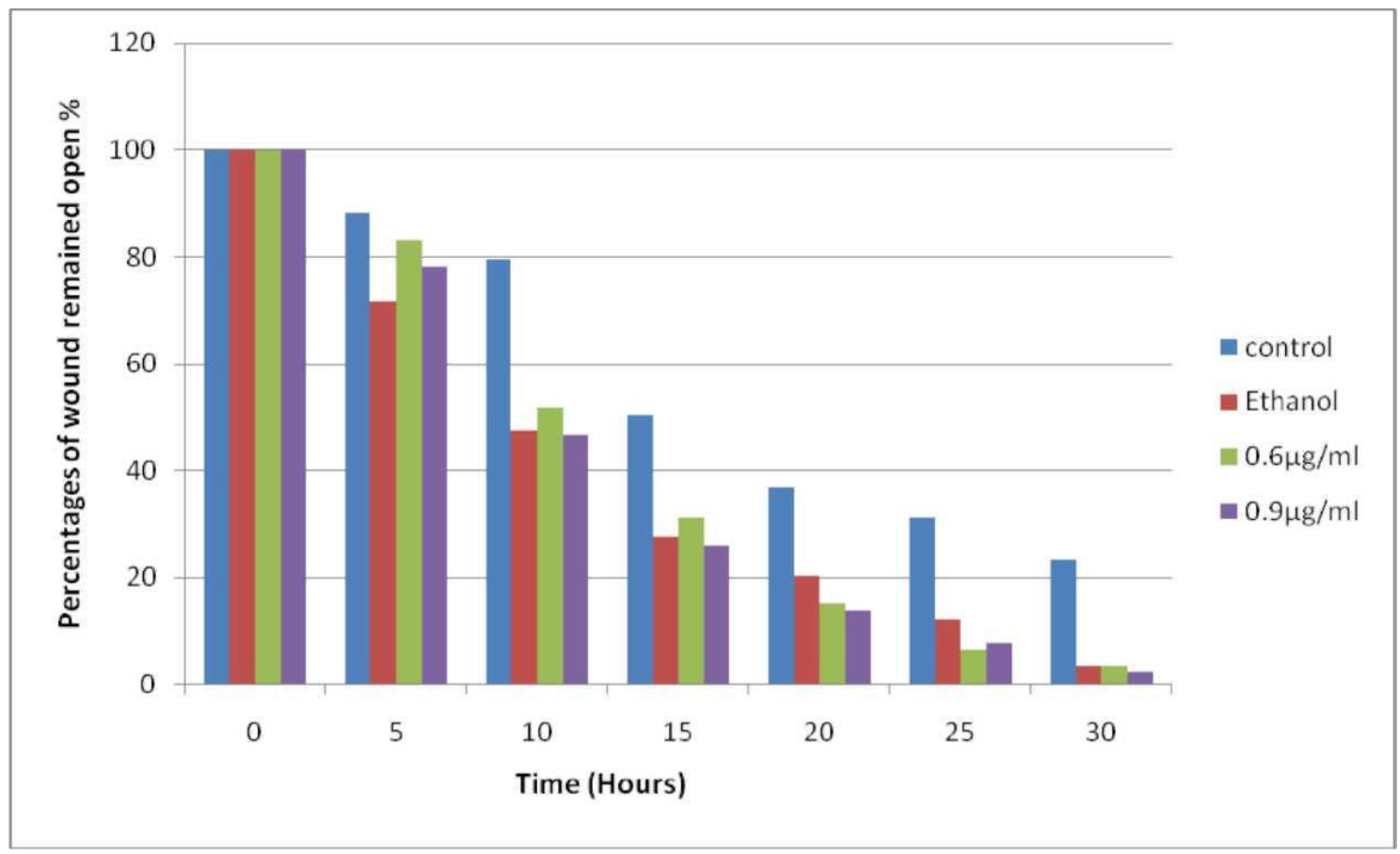

(A)

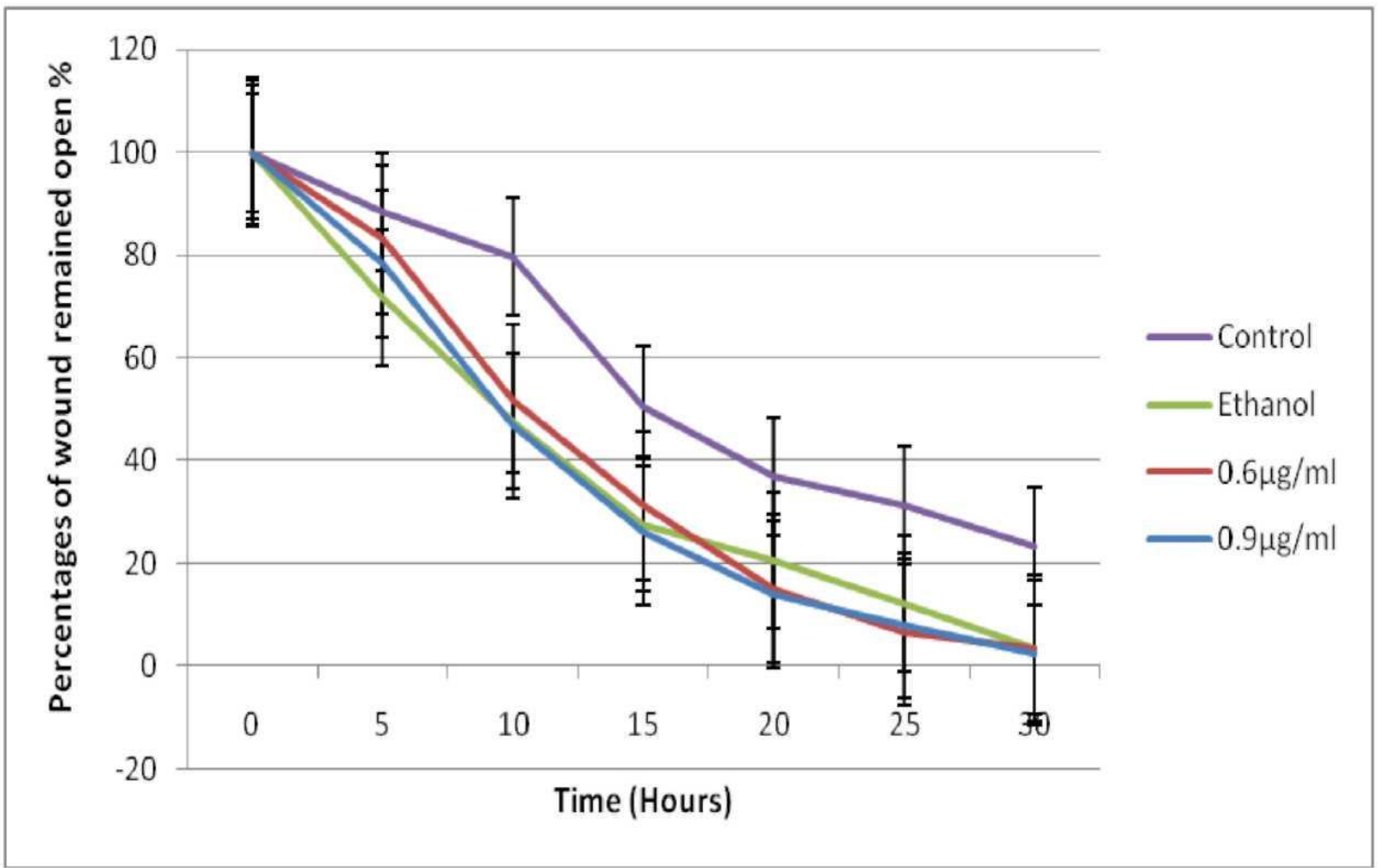

(B)

Figure 3 (A) Bar chart, and (B) Graph of \% wound remained open versus time for control, ethanol, and different concentrations of cannabinoids

(WIN 55,212-2). 


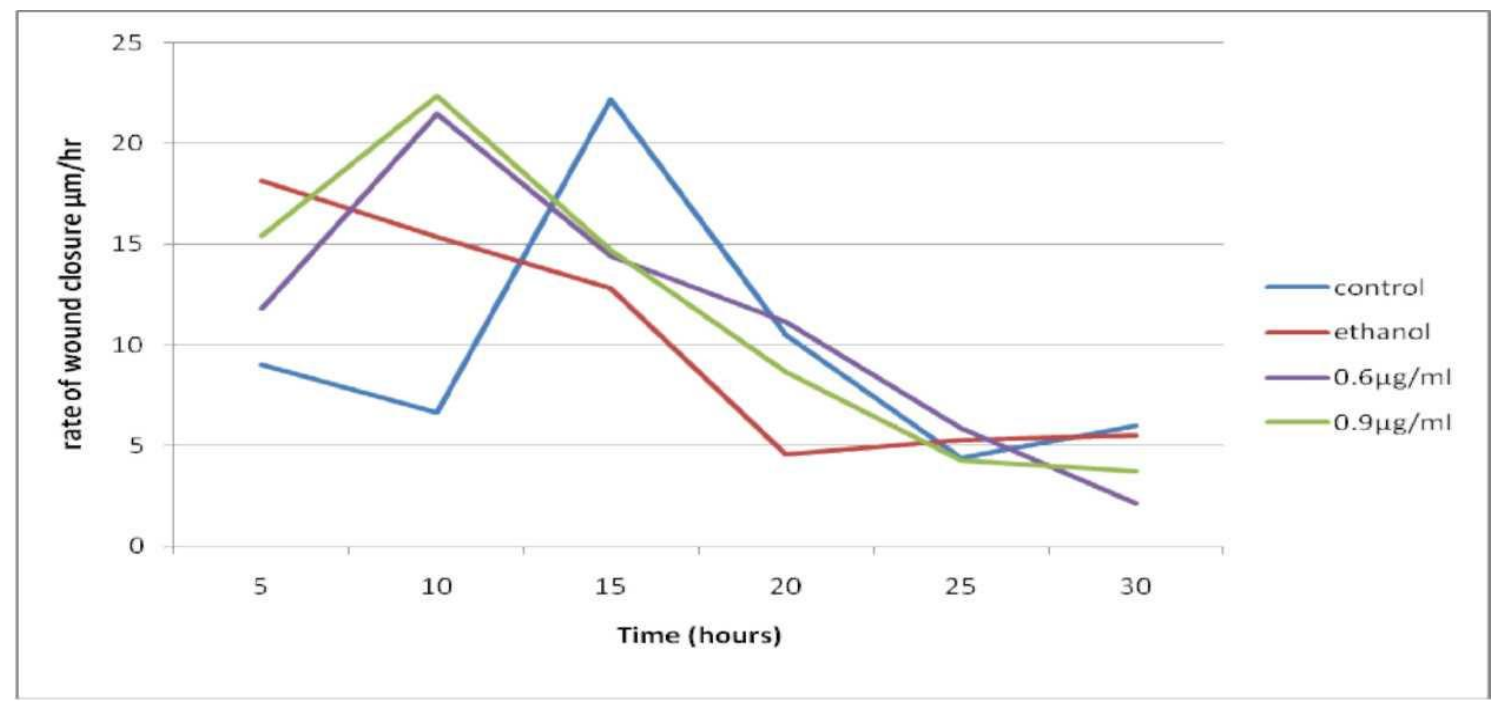

Figure 4 Rate of wound closure $(\mu \mathrm{m} / \mathrm{hr})$ versus time for control, ethanol and different concentrations of cannabinoids.

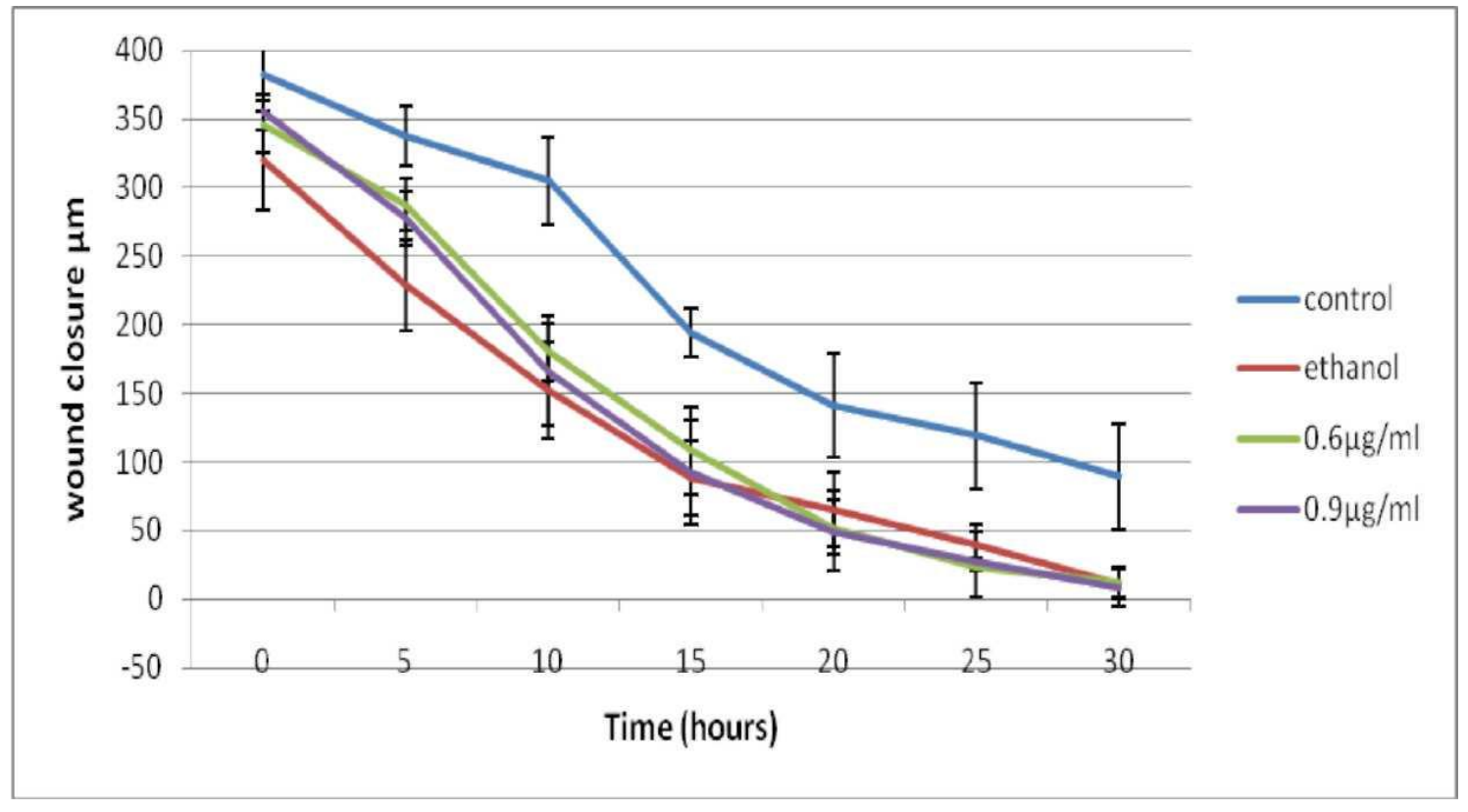

Figure 5 Wound closure versus time over a period of $\mathbf{3 0}$ hours for control, ethanol and different concentrations of cannabinoids.

Table 1 Summary of the slope (gradient) for the wound closure curves in Figure 5.

\begin{tabular}{l|l}
\hline Control & $\mathrm{y}=42.354 \mathrm{x}$ \\
\hline Ethanol & $\mathrm{y}=48.033 \mathrm{x}$ \\
\hline $0.6 \mu \mathrm{g} / \mathrm{ml}$ & $\mathrm{y}=52.329 \mathrm{x}$ \\
\hline $0.9 \mu \mathrm{g} / \mathrm{ml}$ & $\mathrm{y}=54.856 \mathrm{x}$ \\
\hline
\end{tabular}




\section{Conclusions}

By comparing all the treatments with respect to time required for complete wound closure, all treatments demonstrated significant differences in wound repair. Final concentration of $0.9 \mu \mathrm{g} / \mathrm{ml}$ cannabinoid WIN-2 appeared to heal at a faster rate than $0.6 \mu \mathrm{g} / \mathrm{ml}$ and both faster than ethanol and control. This indicates the positive effect of WIN-2 cannabinoid in the process of wound healing and in playing major roles in both cell proliferation and cell migration. The slopes of the wound closure rate showed almost liner increase in the rate of wound closure up to $\sim 15$ hours emphasizing on the accelerated wound closure due to the administration of the synthetic cannabinoid WIN 55,212-2. Proliferation tests also showed that WIN-2 cannabinoid increased the rate of wound closure by increasing cell proliferation, i.e. by increasing the number of cells. It is, therefore, believed that the synthetic cannabinoid WIN 55,212-2 used on wounded bone cell monolayers prevented further resorption and damage by perhaps inhibiting proteoglycan degradation. Several other reasons such as maintenance of healthy bone cells may also play important roles in the effectiveness of cannabinoid in bone monolayer wound repair as well as the ability of WIN 55,212-2 to reduce IL-1 1 induced nitric oxide $(\mathrm{NO})$.

\section{References}

[1] I. Bab and A. Zimmer, Cannabinoid receptors and the regulation of bone Mass. British Journal of Pharmacology (2008) 153 182-188.

[2] A.C. Porter and C.C. Felder, The endocannabinoid nervous system: unique opportunities for therapeutic intervention, Pharmacol Ther 90 (2001), pp. 45-60.

[3] A. Zygmunt, THC and Cannabinol Activate Sensory Nerves, J. Neurosci., June 1, 2002, 22(11):4720-4727 4721

[4] F. Sefat, M. Youseffi, R.F. Berends, S.A. Khaghani, and M.C.T. Denyer, The AntiScarring (Wound Closure) Properties of TGF-B3, BSA/HCl and $\mathrm{HCl}$ in Cultured Human Bone Cell Monolayer, Proceedings of the World Congress on Engineering, WCE 2009, Vol II, July 1 - 3, 2009, London, U.K.

[5] M. Bouaboula, C. Poinot-Chazel, , B. Bourrie, X. Canat, B. Calandra, RinaldiCarmona, M., Le Fur, G., and Casellas, P. (1995), Activation of mitogen-activated protein kinases by stimulation of the central cannabinoid receptor CB1, Biochem J 312, 637- 641.

[6] A. Ofek, Peripheral cannabinoid receptor, CB2, regulates bone mass. Proceedings of the National Academy of Sciences of the United States of America (2006) 103: 696701.

[7] S. Munro, K.L. Thomas and M. Abu-Shaar, Molecular characterization of a peripheral receptor for cannabinoids, Nature 365 (1993), 61-65. 